\title{
On the Optimality of Joint Taxation for Non-Cooperative Couples
}

\author{
Volker Meier \\ Helmut Rainer
}

CESIFO WORKING PAPER NO. 3128

CATEGORY 4: LABOUR MARKETS

JULY 2010
An electronic version of the paper may be downloaded
- from the SSRN website:
- from the RePEc website:
- from the CESifo website:
www.SSRN.com
Www.RePEc.org
www.CESifo-group.org/wp




\title{
On the Optimality of Joint Taxation for Non-Cooperative Couples
}

\begin{abstract}
We present a non-cooperative model of a family's time allocation between work and a homeproduced public good, and examine whether the income tax should apply to couples or individuals. While tax-induced labor supply distortions lead to overprovision of the public good, spouses' failure to internalize the collective effect of their choices points towards underprovision. A large parameter range exists for which a move from individual to joint taxation improves the welfare of both spouses. The source of Pareto-improvement consists in moving the level of the public good closer to its first-best, while an adjustment of intra-family transfers compensates the secondary earner for the increased tax load.
\end{abstract}

JEL-Code: D13, D62, H23, H24, J22.

Keywords: individual taxation, joint taxation, household production, public goods.

Volker Meier

Ifo Institute for Economic Research at the University of Munich

Poschingerstrasse 5

81679 Munich

Germany

meier@ifo.de
Helmut Rainer

Ifo Institute for Economic Research at the University of Munich

Poschingerstrasse 5

81679 Munich

Germany

rainer@ifo.de

July 12, 2010 


\section{Introduction}

Economists' view of how couples should be taxed has traditionally rested on the assumption that households are organized efficiently. In this standard approach, joint income taxation is generally seen as detrimental to welfare compared to individual taxation. The argument is simple and has great intuitive appeal: joint taxation takes the household as the taxable unit and implies high marginal taxes to the secondary earner. Since secondary earners, in particular married wives, exhibit comparatively high labor supply elasticities, joint taxation induces stronger distortions of labor supply than individual taxation (Apps and Rees, 1999a,b; Gottfried and Richter, 1999). Many economists therefore advocate to replace joint taxation by individual taxation. In this paper, we challenge the results emanating from the cooperation-based family taxation literature by showing that joint taxation may Pareto-dominate individual taxation if family members cannot commit to efficient patterns of behavior.

Our key result is obtained under the assumption that family members neither have an incentive to strike bargains involving binding commitments, nor are able to implicitly enforce efficient outcomes through repeated interaction. Instead we assume that decisionmaking in the family can be formulated as a non-cooperative game. This may be justified on three grounds. First, it is well understood that cooperative bargaining is distinguished from non-cooperative behavior by the ability of players to make binding agreements. The implementation and enforcement of cooperative agreements within marriage typically requires couples to incur transaction costs (Pollak, 1985). Noncooperation, in contrast, avoids these costs. Thus, if the transaction costs associated with a cooperative bargain are sufficiently high, it will be optimal for a couple to remain at a non-cooperative solution. Second, much of the family taxation literature implicitly appeals to folk theorems of the theory of repeated games to argue that efficient household resource can be sustained through repeated interactions. The argument ignores, however, that these results apply if and only if individuals are infinitely patient, i.e., in the limit as discount factors tend to one. Although this limiting case provides a useful theoretical benchmark, the assumption of excessive patience is not particularly plausible. If one allows more realistically for heterogeneity of discount factors, then families would sort endogenously into cooperative and non-cooperative resource allocation regimes (Del Boca and Flinn, 2009). Finally, leaving the preceding theoretical arguments aside, empirical evidence to date has not been able to resolve the question of whether family decision-making is generally efficient. But recognizing the prevalence of wasteful and destructive phenomena at the household level, it seems rather obvious that many families fail to coordinate on efficient courses of 
action.

There are a number of ways of relaxing the assumption that households are organized efficiently. Our approach is to envisage a "seperate spheres" contribution equilibrium (Lundberg and Pollak, 1993) in which socially prescribed gender roles assign the primary responsibility for certain public goods to the wife and others to the husband. To keep things simple, we focus on an allocation in which the wife provides a home-produced public good, which one could think of as time spent with a child, and the husband specializes in the generation of money income, a portion of which he may transfer to his wife. Of course, these roles are reversed if the wife is the primary and the husband the secondary earner. We show that, in this simple non-cooperative environment, joint taxation may welfare-dominate individual taxation. More precisely, parameter ranges can be found where (i) both spouses achieve maximum utility under joint taxation, but also where (ii) both spouses experience a utility gain through a revenue neutral move from joint to individual taxation. When we drop the assumption that one partner is fully specialized in market work and allow both spouses to contribute to the production of the household public good, the parameter range under which joint taxation is optimal even tends to become larger.

The intuition for our results is as follows. Non-cooperative behavior implies that there is no self-enforcing mechanism that induces the wife to internalize the impact of her choices on the husband. As a consequence, the wife tends to supply an inefficiently high amount of time to the labor market, implying an inefficiently low provision of the household public good. This problem is mitigated to some extent by the unconditional transfer from the husband to the wife. At the same time, income taxation distorts labor supply downwards. Noting the negative externality of labor supply, the payroll tax works like a Pigouvian tax. It may well be the case that high marginal taxes as generated by joint taxation are necessary to correct the negative externality in full. Thus, the behavior-induced externality can interact with the tax-induced distortion in such way as to make both spouses better off under joint taxation than under individual taxation. After a revenue neutral move from individual to joint taxation, the tax load of the husband generally falls, while the wife faces a higher marginal tax rate. The increase of the marginal tax typically induces a stronger labor supply response from the wife to a variation in the transfer from the husband. Due to his higher net income and a lower implicit price of the home-produced public good, the husband tends to increase his transfer. In equilibrium, the higher transfer often compensates for the higher tax load of the wife. Moreover, the undersupply of the household public good is reduced. Therefore, both individuals may enjoy higher utility 
under joint taxation, while the budget of the government remains balanced. For some extreme cases, there is already oversupply of the public good under individual taxation due to very high marginal tax rates. In that event, moving to joint taxation would deteriorate welfare further. When both spouses contribute to the public good, the structure of home production becomes an additional source of inefficiency. The advantage of joint taxation for tackling that problem can be traced back to its property of not distorting relative input prices, as already stressed by Piggott and Whalley (1996).

Our work is related to the theoretical literature on family taxation. The standard argument to replace joint by individual taxation as stated at the outset remains true even if the endogeneity of fertility is taken into account (Meier and Wrede, 2008). Optimal taxation theory in the Ramsey tradition even calls for selective taxation where women are taxed at lower rates than men (Apps and Rees, 2007) or that marginal taxation of one individual decreases in the income of the spouse (Kleven et al., 2009). While we too are interested in the choice of tax unit, our focus is on how to optimally tax non-cooperative couples. Non-cooperation implies that there is an additional distortion-one that does not appear in efficiency-based models of household behavior. We show that the typical behavior-induced externality of the noncooperative framework generates a large range of parameter values for which a move from individual taxation to joint taxation improves the welfare of both spouses.

Our contribution is also related to the literature on non-cooperative family decisionmaking. The seminal study in this area is by Konrad and Lommerud (1995) who develop a non-cooperative model of a couple's time allocation. Their key finding is that it is possible to influence the intra-family equilibrium outcome by lump-sum redistribution from one partner to the other, and that such redistribution might lead to a Pareto-improvement. Another close antecedent is Chen and Woolley (2001) who consider a family model in which two partners choose the amount of a household public good non-cooperatively. They demonstrate that targeting of benefits within families matters, but take the labor supply decisions of family members as exogenous. The non-cooperative approach has also been adopted by Anderberg (2007) who analyzes the mix of government spending when family behavior is inefficient. Rasul (2006) and Rainer (2007) study non-cooperative investments in public goods like child quality where the divorce law is the policy variable.

The remainder of this paper is organized as follows. The next section lays out our basic model and Section 3 derives its equilibrium. Section 4 characterizes the efficient allocation of resources. Section 5 examines the optimal choice of tax unit. Section 6 elaborates an extension in which both spouses can contribute to the production of the 
household public good. Section 7 discusses some caveats to our approach and Section 8 concludes.

\section{The basic model}

Consider a representative household consisting of husband $(m)$ and wife $(f)$. Both family members have a unit of time endowment, and can earn a gross wage in the labor market equal to $w_{i}(i=m, f)$. Individual $i$ 's preferences are represented by a strictly increasing and strictly quasi-concave utility function defined over a private good, $c_{i}$, and a homeproduced public good, $q$. Since our objective is to provide a model that is tractable and, at the same time, highlights why the couple may enjoy higher welfare under joint taxation than under individual taxation, we consider a logarithmic utility representation of preferences:

$$
\begin{aligned}
U^{m}\left(c_{m}, q\right) & =\ln c_{m}+\beta_{m} \ln q, \\
U^{f}\left(c_{f}, q\right) & =\ln c_{f}+\beta_{f} \ln q,
\end{aligned}
$$

where $\beta_{f}>0$ and $\beta_{m}>0$ are constant preference parameters. Although the specification is somewhat restrictive in implying homotheticity of preferences, it already allows for a rich structure of outcomes, in particular the Pareto dominance of joint taxation over individual taxation and vice versa. For simplicity, only the wife contributes to the public good, which is described as home production. The wife's total time endowment can be spent on working $(\ell)$ or used for home production $(q)$,

$$
q=1-\ell
$$

The husband spends his time endowment working in the labor market, where he receives the gross wage $w_{m}$. The only way in which the husband can affect the time allocation decision of the wife is through a monetary transfer $\theta \geq 0$.

The consumption levels of the husband and the wife depend on the tax treatment of couples and are respectively given by

$$
\begin{aligned}
c_{f} & =w_{f} \ell\left[1-\alpha \tau_{f}-(1-\alpha) \tau_{j}\right]+\theta, \\
c_{m} & =w_{m}\left[1-\alpha \tau_{m}-(1-\alpha) \tau_{j}\right]-\theta .
\end{aligned}
$$

Under joint taxation $(\alpha=0)$ the marginal tax rate $\tau_{j}$ is the same for both spouses. Individual taxation $(\alpha=1)$ by contrast has the individual as the tax unit, where wage income is taxed separately at exogenous marginal rates $\tau_{m}$ and $\tau_{f}$. Throughout the paper 
we assume that $\tau_{m}>\tau_{f}$. This assumption mirrors a progressive income tax schedule, where the wage of the wife falls short of the wage of the husband. ${ }^{1}$ For convenience,

$$
w_{i}^{n}=w_{i}\left[1-\alpha \tau_{i}-(1-\alpha) \tau_{j}\right]
$$

denotes the net wage of individual $i=m, f$.

The sequence of events is as follows. First, the government commits to either joint or individual taxation by announcing $\alpha \in\{0,1\}$. Second, the husband chooses $\theta$ to maximize $U^{m}\left(w_{m}^{n}-\theta, q\right)$ subject to the wife's reaction function $q(\theta)=1-\ell(\theta)$. Finally, the wife chooses her labor supply $\ell$ to maximize $U^{f}\left(w_{f}^{n} \ell+\theta, 1-\ell\right)$, which at the same time determines the level of the home-produced public good $q$. Thus, in equilibrium we have $\theta^{*}\left(\alpha, \tau_{j}\right)$ and $\ell^{*}\left(\alpha, \tau_{j}, \theta^{*}\left(\alpha, \tau_{j}\right)\right)$. The joint marginal tax rate $\tau_{j}$ is determined by keeping aggregate tax revenue at the equilibrium level under individual taxation. Thus, $\tau_{j}$ satisfies

$$
\tau_{m} w_{m}+\tau_{f} w_{f} \ell^{*}\left(1, \tau_{j}, \theta^{*}\left(1, \tau_{j}\right)\right)=\tau_{j}\left[w_{m}+w_{f} \ell^{*}\left(0, \tau_{j}, \theta^{*}\left(0, \tau_{j}\right)\right)\right]
$$

Solving this noncooperative game of complete information between the husband and the wife, the next subsection deals with the choices of the two family members in reverse order. We focus on the unique subgame perfect equilibrium of this game and refer to this just as the equilibrium in what follows.

\section{Family resource allocation game}

Given the transfer $\theta \geqslant 0$ made by the husband, the wife has to decide how to allocate her time between market work $\ell$ and home production $q$. She chooses $\ell \in[0,1]$ to solve

$$
\max _{\ell \in[0,1]}\left[\ln \left(w_{f}^{n} \ell+\theta\right)+\beta_{f} \ln (1-\ell)\right]
$$

Lemma 1 summarizes the results on labor supply of the wife:

Lemma 1. Labor supply of the wife is given by $\ell^{*}(\theta)=\max \{0, \tilde{\ell}(\theta)\}$ with

$$
\tilde{\ell}(\theta)=\frac{1}{1+\beta_{f}}-\frac{\beta_{f} \theta}{\left(1+\beta_{f}\right) w_{f}^{n}} .
$$

The interior solution emerges for $\theta<\hat{\theta} \equiv w_{f}^{n} / \beta_{f}$. In that case, the reaction of the wife to a higher transfer is

$$
\frac{\partial \tilde{\ell}}{\partial \theta}=-\frac{\beta_{f}}{\left(1+\beta_{f}\right) w_{f}^{n}}<0,
$$

\footnotetext{
${ }^{1}$ Should the wage of the wife exceed the wage of the husband, it would be natural to assign the role of the primary earner to her, where the husband would be the only or main producer of the household public good. In that event, the labels 'husband' and 'wife' have to be exchanged throughout.
} 
where, at given transfer $\theta$, a higher marginal tax rate reduces $\tilde{\ell}$ and increases $\left|\frac{\partial \tilde{\ell}}{\partial \theta}\right|$.

Proof. See the Appendix.

Without a transfer from her husband, labor supply of the wife is independent of any tax rate and of the wage. This is a consequence of the logarithmic utility representation of preferences, where income and substitution effects offset each other. A higher transfer reduces labor supply of the wife, as it enables her to consume more goods and at the same time spend more time on home production. The reaction of labor supply to a higher transfer is independent of the level of the transfer as long as labor supply is positive. Furthermore, a higher marginal tax rate reduces the net wage of the wife and hence the opportunity cost of home production. This in turn decreases labor supply and strengthens the negative reaction of labor supply to an increase in exogenous income through a higher transfer.

Notice that the absolute of the inverse reaction term,

$$
\rho \equiv \frac{\left(1+\beta_{f}\right) w_{f}^{n}}{\beta_{f}},
$$

can be interpreted as the price the husband faces for an additional unit of home production time of the wife. In what follows, we will refer to $\rho$ as the perceived price of the household public good. Comparing $\rho$ to the actual resource cost $w_{f}$ reveals that the perceived price is driven down by taxation of the wage of the wife and up by $\left(1+\beta_{f}\right) / \beta_{f}$. The latter is due to the fact that the wife will use the transfer partially for own consumption.

The next step is to determine the husband's transfer $\theta$. His optimization problem is to solve

$$
\max _{\theta \in\left[0, w_{m}^{n}\right]}\left[\ln \left(w_{m}^{n}-\theta\right)+\beta_{m} \ln \left(1-\ell^{*}(\theta)\right)\right]
$$

The optimal transfer is characterized in Lemma 2.

Lemma 2. The chosen transfer can be expressed as $\theta^{*}=\max \{0, \min \{\tilde{\theta}, \hat{\theta}\}\}$ with

$$
\tilde{\theta}=\frac{\beta_{m} w_{m}^{n}-w_{f}^{n}}{1+\beta_{m}}
$$

and $\hat{\theta} \equiv w_{f}^{n} / \beta_{f}$. In case of the interior solution, $\theta^{*}=\tilde{\theta}$, the transfer increases with a higher preference parameter for the public good of the husband, $\beta_{m}$, is independent of the preference parameter for the public good of the wife, $\beta_{f}$, rises with the net wage of the husband and falls with the net wage of the wife.

Proof. See the Appendix. 
A positive transfer requires that the husband's net wage multiplied by the preference parameter $\beta_{m}$ exceeds the wife's net wage. Otherwise the preferred transfer will be zero. An upper bound of the transfer is reached when labor supply of the wife touches zero, as further increases reduce the consumption possibilities of the husband without increasing the provision of the public good. The specification of the utility functions leads to irrelevance of the wife's preference parameter for the chosen transfer of the husband, as two effects cancel each other out: while the higher level of time used in the production of the household public good tends to depress the transfer, the stronger reaction of labor supply to a higher transfer works in the opposite direction.

The equilibrium of the resource allocation game has three possible regimes: the interior solution, the no-transfer equilibrium, and the no-participation equilibrium. In order to summarize the conditions under which these three regimes emerge, define

$$
\underline{w}_{m}(\alpha)=\frac{w_{f}^{n}}{\beta_{m}\left[1-\alpha \tau_{m}-(1-\alpha) \tau_{j}\right]}
$$

and

$$
\bar{w}_{m}(\alpha)=\frac{\left(1+\beta_{m}+\beta_{f}\right) w_{f}^{n}}{\beta_{m} \beta_{f}\left[1-\alpha \tau_{m}-(1-\alpha) \tau_{j}\right]} .
$$

Here $\underline{w}_{m}$ is that value of $w_{m}$ for which $\tilde{\theta}=0$, while $\bar{w}_{m}$ solves $\tilde{\theta}=\hat{\theta}$. Now, for $w_{m} \in$ $\left(\underline{w}_{m}, \bar{w}_{m}\right)$, neither family member is bound by non-negativity constraints and an interior equilibrium with $\theta^{*}=\tilde{\theta}$ and $\ell^{*}=\tilde{\ell}(\tilde{\theta})$ turns out. For $w_{m} \leqslant \underline{w}_{m}$, the husband's nonnegativity constraint binds and a "no-transfer" equilibrium with $\theta^{*}=0$ and $\ell^{*}=\tilde{\ell}(0)$ emerges. If $w_{m} \geqslant \bar{w}_{m}$, the wife's non-negativity constraint binds and a "no-participation" equilibrium with $\theta^{*}=\hat{\theta}$ and $\ell^{*}=0$ is the outcome.

From the above definitions it is also readily checked that an interior equilibrium exists under both joint taxation $(\alpha=0)$ and individual taxation $(\alpha=1)$ if and only if $\bar{w}_{m}(0)>$ $\underline{w}_{m}(1)$, which yields the following condition on $\tau_{m}$ :

$$
\tau_{m}<1-\frac{\beta_{f}\left(1-\tau_{f}\right)}{1+\beta_{m}+\beta_{f}} \equiv \tau_{i n t} .
$$

\section{First-best public good provision}

In order to have a benchmark against which we can compare the equilibrium of the family resource allocation game, we now consider the first-best level of public good provision. Throughout we assume that the government has a tax revenue requirement which is equivalent to the equilibrium tax revenue under individual taxation. 
For any Pareto optimum, the efficient level of public good provision is determined by the well-known Samuelson condition:

$$
\sum_{i=f, m} \frac{\beta_{i} c_{i}}{q}=w_{f} .
$$

Here $\beta_{i} c_{i} / q$ is individual $i$ 's marginal rate of substitution between the public and the private good, while $w_{f}$ represents the marginal rate of transformation between the public and the private good. Letting $\tilde{t}$ denote aggregate tax revenue under individual taxation, the resource constraint reads

$$
c_{m}+c_{f}+w_{f} q=w_{m}+w_{f}-\tilde{t} .
$$

Together with the resource constraint (18), the Samuelson condition (17) determines the first-best level of the home-produced public good. In case of identical preference parameters, $\beta_{f}=\beta_{m} \equiv \beta$, we obtain

$$
q^{e}=\min \left\{\frac{\beta\left(w_{f}+w_{m}-\tilde{t}\right)}{(1+\beta) w_{f}}, 1\right\},
$$

where the level of the public good is independent of the distribution of private consumption. Moreover, the first-best level of the public good increases with the preference parameter $\beta$ and falls with a higher resource cost $w_{f}$. If $\beta_{f} \neq \beta_{m}$, the Samuelson condition and the resource constraint still jointly determine the set of efficient allocations. But relatively more consumption for the individual with a stronger taste for the public good will be associated with a higher optimal provision level, and vice versa.

\section{The optimal choice of tax unit}

We now consider the question of when and why joint taxation can emerge as the optimal tax scheme, focusing on the interior equilibrium in which neither family member is bound by non-negativity constraints. To illustrate the set of possible outcomes in a clear and simple fashion, we take the assumption $\beta_{f}=\beta_{m}=1$. Thus, the private and the public good have equal weight in the utility function of both family members.

To begin with, as we consider revenue neutral tax policy changes, the government has to choose $\tau_{j}$ under joint taxation such that aggregate tax revenue remains at the equilibrium level under individual taxation. For the interior equilibrium, it is straightforward to establish the following intermediate result.

Lemma 3. When $\beta_{m}=\beta_{f}=1$ and the interior equilibrium prevails, the revenue-neutral marginal tax rate under joint taxation $(\alpha=0)$ is given by

$$
\tilde{\tau}_{j}=\frac{\tau_{m} w_{m}+\tau_{f} w_{f}}{w_{m}+w_{f}}+\frac{w_{m}\left(\tau_{m}-\tau_{f}\right)}{3\left(w_{m}+w_{f}\right)\left(1-\tau_{f}\right)}
$$


Proof. See the Appendix.

Note that the marginal tax rate under joint taxation will exceed the tax rate of the husband under individual taxation, $\tilde{\tau}^{j}>\tau_{m}$, if and only if $w_{m}>3 w_{f}\left(1-\tau_{f}\right)$. In that case, a high wage differential exists, implying that the share of the wife in total tax payment of the household is low already under individual taxation, while the transfer from husband to wife is high.

Next, we compare the first-best and the private provision level of the household public good under joint and individual taxation. Focusing on interior equilibria with $\theta^{*}=\tilde{\theta}$ and $\ell^{*}=\tilde{\ell}(\tilde{\theta})$, the private provision level of the public good is

$$
\tilde{q}(\tilde{\theta})=1-\tilde{\ell}(\tilde{\theta})=\frac{1}{4}+\frac{w_{m}^{n}}{4 w_{f}^{n}}
$$

where $w_{i}^{n}=w_{i}\left[1-\alpha \tau_{i}-(1-\alpha) \tau_{j}\right]$. The first-best provision level is

$$
q^{e}=\frac{1}{2}+\frac{w_{m}-\tilde{t}}{2 w_{f}}
$$

Comparing (21) and (22), we have the following result:

Proposition 1. When $\beta_{m}=\beta_{f}=1$ and $\tau_{m}>\tau_{f}$, the equilibrium provision of the household public good relative to the first-best is as follows. Let

$$
\tilde{\tau}_{m}\left(\tau_{f}\right)=\frac{8+\tau_{f}\left(3 \tau_{f}-8\right)}{4-3 \tau_{f}} \quad \text { and } \quad \mu=\frac{\left(2-3 \tau_{f}\right)\left(1-\tau_{f}\right)}{2\left(1-\tau_{f}\right)-\left(1-\tau_{m}\right)\left(4-3 \tau_{f}\right)} .
$$

Then:

a. For $\tau_{m}>\tau_{f}>2 / 3$, the household public good is overprovided under both individual and joint taxation.

b. For $\tau_{m}>2 / 3>\tau_{f}$, the public good is overprovided under joint taxation but underprovided under individual taxation.

c. For $\tau_{m} \in\left(\tilde{\tau}_{m}, 2 / 3\right)$, two cases may arise: if $w_{m}>\mu w_{f}$, there is overprovision under joint taxation but underprovision under individual taxation; if $w_{m}<\mu w_{f}$, there is underprovision under both tax regimes.

d. For $\tau_{m}<\tilde{\tau}_{m}$, the public good is underprovided under both individual and joint taxation.

Proof. See the Appendix.

Figure 1 illustrates this result. First, the possible parameter values giving rise to an interior equilibrium under both tax regimes comprise the region below the line labeled 


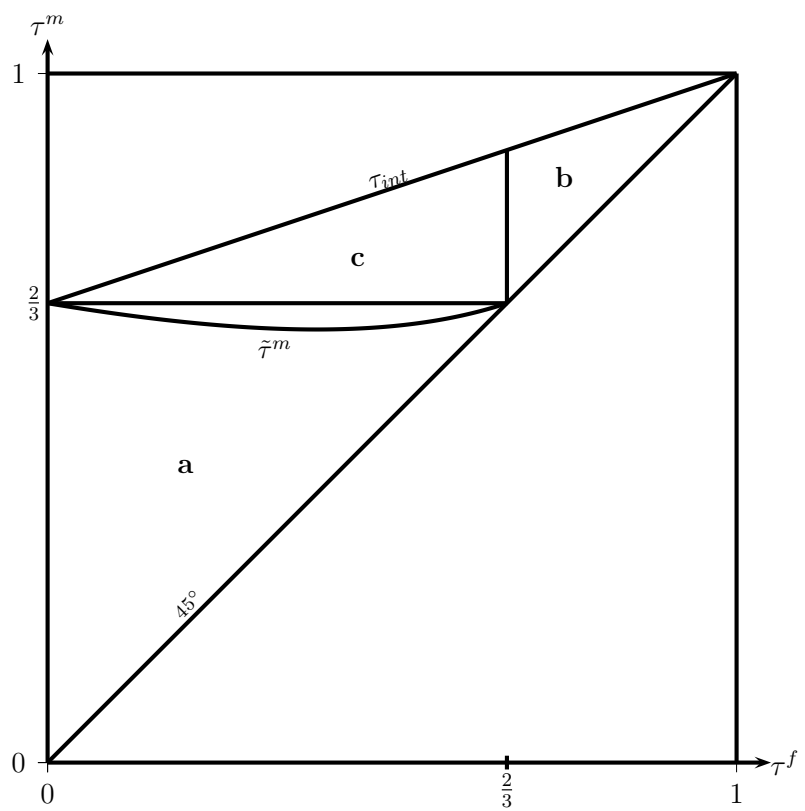

FiguRE 1: Overprovision and underprovision regimes.

$\tau_{\text {int }}$. Within that region, there are parameter ranges where, independently of how couples are taxed, the equilibrium provision of the home-produced public good is inefficiently low (region a). This case arises when the tax revenue requirement is moderate, so that individual tax rates are in a normal range and the perceived price of the home-produced public good is high. Next, there are parameter ranges where, irrespective of the tax regime, the equilibrium level of the public good is inefficiently high (region b). This scenario occurs when the government's revenue requirement implies very high marginal tax rates. Finally, with some intermediate marginal tax rates, the equilibrium public good level is inefficiently high with joint taxation and inefficiently low with individual taxation (region $\mathbf{c})$.

Having described the efficiency properties of the household equilibrium, we now turn our attention to the main issue of concern, namely the characterization of the optimal tax scheme. To this end, we compare individual utilities under joint taxation $(\alpha=0)$ and individual taxation $(\alpha=1)$. Using $\beta_{f}=\beta_{m}=1$, it is easy to check that the interior equilibrium utility level of family member $i(i=f, m)$ under joint taxation is

$$
\tilde{U}_{J}^{i}=\Gamma_{i}+\ln \left[\frac{\left(1-\tau_{j}\right)\left(w_{m}+w_{f}\right)^{2}}{w_{f}}\right],
$$

where $\Gamma_{i}$ is a constant. The indirect utility of family member $i(i=f, m)$ under individual taxation is

$$
\tilde{U}_{I}^{i}=\Gamma_{i}+\ln \left[\frac{\left(w_{m}\left(1-\tau_{f}\right)+w_{f}\left(1-\tau_{f}\right)\right)^{2}}{w_{f}\left(1-\tau_{m}\right)}\right]
$$



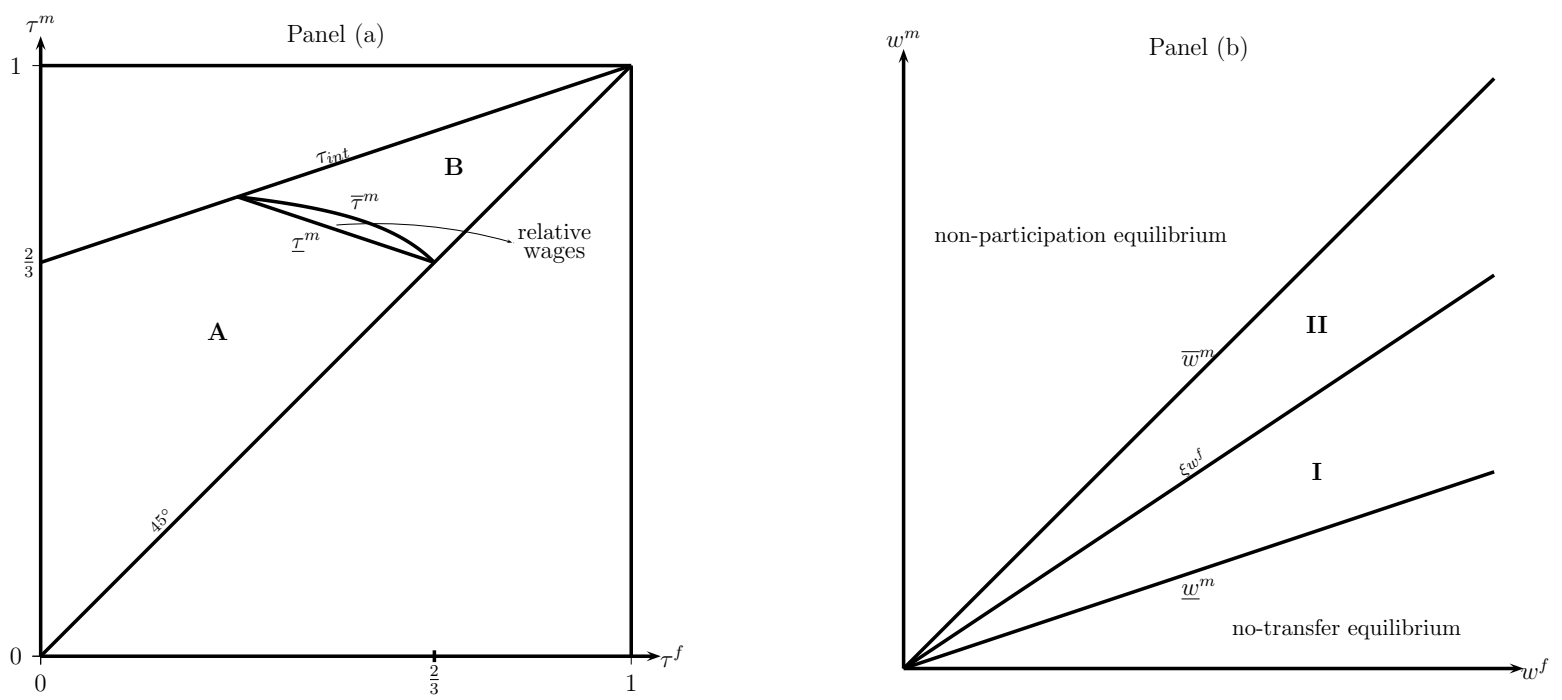

Figure 2: Optimal tax regime regions.

Comparing (23) with (24), we obtain the main result of the paper:

Proposition 2. Let $\beta_{m}=\beta_{f}=1$ and $\tau_{m}>\tau_{f}$. Consider the interior equilibrium of the resource allocation game with $\theta^{*}=\tilde{\theta}$ and $\ell^{*}=\tilde{\ell}(\tilde{\theta})$. Then there exist two thresholds $\underline{\tau}_{m}\left(\tau_{f}\right)$ and $\bar{\tau}_{m}\left(\tau_{f}\right)$ defined by

$$
\underline{\tau}_{m}\left(\tau_{f}\right)=\frac{8-3 \tau_{f}}{9}<\frac{5 \tau_{f}-4}{6 \tau_{f}-5}=\bar{\tau}_{m}\left(\tau_{f}\right)
$$

such that:

a. For $\tau_{m}<\underline{\tau}_{m}$, both family members enjoy maximum utility under joint taxation $(\alpha=0)$ with the revenue-neutral marginal tax rate $\tilde{\tau}^{j}$.

b. For $\tau_{m}>\bar{\tau}_{m}$, both family members enjoy maximum utility under individual taxation $(\alpha=1)$.

c. For $\tau_{m} \in\left(\underline{\tau}_{m}, \bar{\tau}_{m}\right)$, the optimal tax scheme depends on relative wages. Formally, there exists a coefficient

$$
\xi=\frac{2-3 \tau_{f}}{3 \tau_{m}-2}
$$

such that both family members enjoy maximum utility under joint taxation (respectively, individual taxation) if $w_{m}<\xi w_{f}$ (respectively, if $\left.w_{m}>\xi w_{f}\right)$.

Proof. See the Appendix.

This result contains the key message of the paper: joint taxation may Pareto-dominate individual taxation if family members fail to coordinate on efficient patterns of behavior.

Figure 2 illustrates. In region $\mathbf{A}$, both family members enjoy maximum utility under joint taxation. When the government's revenue requirement is moderate such that $\tau_{m}$ 
and $\tau_{f}$ are not too large, the price the husband faces for buying additional units of home production time from his wife exceeds the resource cost, ultimately resulting in undersupply of the public good. This situation is alleviated by moving from individual taxation to joint taxation. The perceived price of the household public good falls, and pre-transfer income is redistributed from the wife to the husband. With the specification under consideration, a large fraction of redistributed income is used for being retransferred to the wife. The additional transfer reinforces the already positive impact of the initial transfer on the provision of the public good. Consequently, the provision of the public good gets closer to the efficient level, and through the transfer mechanism both partners enjoy higher utility.

In region $\mathbf{B}$, individual taxation is optimal. If individual taxes rates are high and not too dispersed, the husband's price for purchasing additional units of time from his wife falls short of the resource cost, and the equilibrium level of the household public good is inefficiently high. In this case, moving from joint taxation to individual taxation increases the perceived price of the public good and reduces the husband's means. This results in lower transfers that at the same time become less effective in increasing the wife's home-production time. Thus, the source of the utility gain for both spouses again consists in moving the provision of the public good closer to the efficient level.

Finally, there exists a small parameter range $\mathbf{C}$ where optimality in taxation depends on relative wages. Note that region $\mathbf{A}$ always comprises the underprovison region $\mathbf{a}$, and region $\mathbf{B}$ always comprises the overprovision region $\mathbf{b}$. Region $\mathbf{C}$ is a subset of region c in which the equilibrium public good level is inefficiently high with joint taxation and inefficiently low with individual taxation. In this case, if the husband's gross wage is high relative to his wife's, then the underprovision problem under individual taxation is less severe than the overprovision problem under joint taxation, and so both family members enjoy maximum utility when they are taxed individually (region II). Conversely, if the spouses have similar wage rates, then joint taxation is more effective in alleviating the overprovision problem than individual taxation is in eroding the underprovision problem, and so both spouses are better off under joint taxation (region I).

It turns out that an optimal tax policy inducing first-best public good provision looks as if it establishes a Lindahl equilibrium. Under individual taxation, the first-best is achieved by setting $\tau_{f}=2 / 3$. In this case, the price of the public good for the wife, $w_{f} / 3$, and its perceived price from the point of view of the husband, $2 w_{f} / 3$, add up to the marginal cost of the good, $w_{f}$. Furthermore, the demand for the public good by the husband at his Lindahl price equals the demand for the public good of the wife at her 
price, which mirrors the unanimity condition of the Lindahl equilibrium. Under joint taxation, the first-best public good provision will be obtained whenever the endogenous joint tax rate is at $\tau_{j}=2 / 3$, which yields the same individualized prices. Underprovision of the public good turns out if the sum of the personal prices exceeds the gross wage of the wife, and overprovision occurs if the sum of these two prices falls short of the marginal resource cost of the public good.

Our discussion so far has focused on the effects of shifting from individual to joint taxation in the interior equilibrium of our model. However, the property of symmetry of interests as regards to tax policy up to now cannot be generalized, as can be seen by analyzing tax reforms in the "no-transfer" equilibrium:

Proposition 3. Let $\beta_{m}=\beta_{f}=1$ and $\tau_{m}>\tau_{f}$. Consider the no-transfer equilibrium of the resource allocation game with $\theta^{*}=0$ and $\ell^{*}=\tilde{\ell}(0)$. Then the wife achieves maximum utility under individual taxation $(\alpha=1)$, while the husband's utility is maximized under joint taxation $(\alpha=0)$.

Proof. See the Appendix.

Proposition 3 shows that a tax policy reform may have asymmetric effects on intrahousehold utility levels. If the equilibrium transfer from the husband to the wife is zero, switching to individual taxation is beneficial for the wife as her tax load goes down. At the same time, the husband would suffer from the reduction of the home-produced public good due to her increased labor supply. A similar argument applies to the "no-participation" equilibrium. Suppose that the wife's equilibrium labor supply is zero and is achieved by means of a positive transfer under individual taxation. Moving to joint taxation would generally reduce the transfer from the husband to the wife as it becomes more effective, while the labor supply of the wife would remain at zero. In such a situation, the tax reform would only redistribute income from the wife to the husband, and utilities would again move in opposite directions.

\section{Extensions}

So far, we have assumed that the husband spends his entire time endowment working in the labor market. This is of course a strong assumption: in practice, none of the partners may be fully specialized in the generation of money income. Let us now specify a home production technology in which each spouse may contribute time to the production of a household public good $Q$ :

$$
Q=\left[\gamma\left(q_{f}\right)^{\rho}+(1-\gamma)\left(q_{m}\right)^{\rho}\right]^{1 / \rho}
$$


where $q_{i}=1-\ell_{i}$ is the amount of time that spouse $i$ contributes to the production of the public good, $\gamma$ is a relative productivity parameter and $\rho$ determines the elasticity of substitution between the wife's and the husband's labor in household production. Note that our basic model corresponds to the case in which $\gamma=1$. In what follows, we shall restrict ourselves to the case of perfect substitutes $(\rho=1)$ and the case of unit elasticity of substitution $(\rho=0)$. We continue to assume that the husband may make financial transfers to his wife.

\subsection{The case of perfect substitutes $(\rho=1)$}

In this case, the household production function gives rise to isoquants that are straight lines. As before, the wife chooses her time allocation to maximize her utility, taking the time allocation of her husband and the transfer from him as given. Using $\beta_{f}=\beta_{m}=1$, it is straightforward to derive the reaction function for the wife's time allocation:

$$
\tilde{q}_{f}\left(q_{m}, \theta\right)=\frac{1}{2}\left[\frac{w_{f}^{n}+\theta}{w_{f}^{n}}-\frac{(1-\gamma) q_{m}}{\gamma}\right]
$$

The husband chooses his time allocation and monetary transfers to his wife so as to maximize his utility, subject to the way in which she will respond to his choices. The solution to his problem implies the following two conditions:

$$
\begin{gathered}
\frac{w_{m}^{n}}{1-\gamma} \geqslant \frac{w_{m}^{n}\left(1-q_{m}\right)-\theta}{\gamma q_{f}+(1-\gamma) q_{m}} \\
\frac{w_{f}^{n}}{\gamma} \geqslant \frac{w_{m}^{n}\left(1-q_{m}\right)-\theta}{\gamma q_{f}+(1-\gamma) q_{m}}
\end{gathered}
$$

Clearly, only one of these can hold with equality if $w_{m}^{n} /(1-\gamma) \neq w_{f}^{n} / \gamma$. Indeed, if the husband has a comparative advantage in market work, only (29) can hold with equality, and if it does so, then there is full specialization in market work by the husband $\left(\tilde{q}_{m}=0\right)$, and he effectively buys home production time from his wife through a voluntary transfer $(\tilde{\theta}>0)$. Thus, a separate spheres equilibrium, as assumed in the basic model, now arises endogenously. In this equilibrium, the wife has the responsibility for the provision of the household public good and the husband specializes in the generation of money income. It follows immediately that, in the case of perfect substitutes, our main results on the optimality of joint taxation for non-cooperative couples remain unchanged.

\subsection{The case of unit elasticity of substitution $(\rho=0)$}

In this case, the household production function corresponds to a Cobb-Douglas function:

$$
Q=\left(q_{f}\right)^{\gamma}\left(q_{m}\right)^{1-\gamma}
$$


Thus the time inputs of the husband and the wife are complements at the margin. The reaction function for the wife's time allocation is:

$$
\tilde{q}_{f}(\theta)=\frac{\gamma\left(w_{f}^{n}+\theta\right)}{w_{f}^{n}(1+\gamma)}
$$

The solution of the utility maximization problem of the husband implies two conditions:

$$
\begin{gathered}
\frac{w_{m}^{n}}{1-\gamma} \geqslant \frac{w_{m}^{n}\left(1-q_{m}\right)-\theta}{q_{m}} \\
\frac{1}{\gamma} \geqslant \frac{w_{m}^{n}\left(1-q_{m}\right)-\theta}{w_{f}^{n}+\theta}
\end{gathered}
$$

It is readily verified that the equilibrium transfer of the husband can be expressed as $\theta^{*}=\max \{0, \tilde{\theta}\}$ with

$$
\tilde{\theta}=\frac{\gamma w_{m}^{n}-(2-\gamma) w_{f}^{n}}{2}
$$

His equilibrium time allocation is given by $q_{m}^{*}=\min \left\{\frac{1-\beta}{2-\beta}, \tilde{q}_{m}\right\}$ where

$$
\tilde{q}_{m}=\frac{(1-\gamma)\left(w_{f}^{n}+w_{m}^{n}\right)}{2 w_{m}^{n}}
$$

In equilibrium, both partners spend time on the production of the household public good. Where does this leave us in the welfare comparison between individual and joint taxation? We do not explicitly characterize the conditions under which joint taxation Paretodominates individual taxation when both spouses contribute to household production. But some thought reveals that joint taxation now has the additional advantage of not distorting the time input structure in household production (Piggott and Whalley, 1996). Individual taxation, by contrast, changes the opportunity cost of each partner's time in household activities asymmetrically and thus distorts the input decisions in household production. The implication is that in the extended model a move from individual to joint taxation can be welfare improving for a larger range of parameter ranges than in the basic model. This is illustrated in Table 1, which reports the results from a simple numerical example. The key message that one can extract from the table is that there exist individual tax rates under which individual taxation welfare-dominates joint taxation in the basic model, but joint taxation is the Pareto-optimal tax scheme in the extended model. Overall, therefore, allowing both couples to contribute to home production only reinforces our Pigouvian argument in favor of joint taxation. 
TABLE 1: Results of a Numerical Example

\begin{tabular}{|c|c|c|}
\hline & \multicolumn{2}{|c|}{$\begin{array}{c}\text { Does Joint Taxation Pareto-Dominate } \\
\text { Individual Taxation? }\end{array}$} \\
\hline & $\begin{array}{l}\text { Basic Model } \\
\qquad\left(\gamma^{b}=1\right)\end{array}$ & $\begin{array}{l}\text { Extended Model } \\
\qquad\left(0<\gamma^{e}<1\right)\end{array}$ \\
\hline \multicolumn{3}{|l|}{ Case $1: \gamma^{b}=1, \gamma^{e}=.5$} \\
\hline$\left(\tau_{f}=.1, \tau_{m}=.3\right)$ & Yes & Yes \\
\hline$\left(\tau_{f}=.4, \tau_{m}=.6\right)$ & Yes & Yes \\
\hline$\left(\tau_{f}=.6, \tau_{m}=.8\right)$ & No & Yes \\
\hline$\left(\tau_{f}=.7, \tau_{m}=.9\right)$ & No & Yes \\
\hline \multicolumn{3}{|l|}{ Case $2: \gamma^{b}=1, \gamma^{e}=.75$} \\
\hline$\left(\tau_{f}=.1, \tau_{m}=.3\right)$ & Yes & Yes \\
\hline$\left(\tau_{f}=.4, \tau_{m}=.6\right)$ & Yes & Yes \\
\hline$\left(\tau_{f}=.6, \tau_{m}=.8\right)$ & No & Yes \\
\hline$\left(\tau_{f}=.7, \tau_{m}=.9\right)$ & No & Yes \\
\hline \multicolumn{3}{|l|}{ Case 3: $\gamma^{b}=1, \gamma^{e}=.95$} \\
\hline$\left(\tau_{f}=.1, \tau_{m}=.3\right)$ & Yes & Yes \\
\hline$\left(\tau_{f}=.4, \tau_{m}=.6\right)$ & Yes & Yes \\
\hline$\left(\tau_{f}=.6, \tau_{m}=.8\right)$ & No & Yes \\
\hline$\left(\tau_{f}=.7, \tau_{m}=.9\right)$ & No & No \\
\hline
\end{tabular}

\section{Discussion}

It is important to air some caveats to the perspective developed so far. The perhaps most controversial feature of our model is that the equilibrium is Pareto-inferior to a cooperative solution, and yet we do not discuss the dynamics of household formation and dissolution. Should we expect individuals to have an incentive to enter marriage, knowing fully well that strategic behavior will prevent them from reaching efficient outcomes? In a recent paper, Barham et al. (2009) highlight the importance of strategic family interactions in determining marriage formation and dissolution. In their model, economies of scale associated with living as a couple rather than as a single provide incentives for marriage, while free riding in the provision of household public goods leads to negative externalities. In equilibrium, stable marriages form when couples are sufficiently similar. But it may be also rational for couples to form strategic marriages anticipating that the 
partnership will subsequently dissolve. Thus, non-cooperative behavior does not eliminate marriage as an equilibrium phenomenon. However, holding everything else constant, free riding in the provision of public goods implies that strategic marriages are more likely to end in divorce than cooperative marriages. For our purposes, it it sufficient that (i) positive externalities in household production exist, (ii) primary earners make unconditional transfers to secondary earners, and (iii) labor supply decisions are not coordinated - which may hold for many couples who behave cooperatively in many other respects.

Another issue our model does not deal with is preference heterogeneity among spouses. However, our results are not special to the case of symmetric preferences. What drives our argument is the recognition that labor supply decisions may constitute an inefficient non-cooperative Nash equilibrium. Family members are induced to work too much and to provide too little of home-produced public goods because of a collective action problem at the household level. Therefore, spousal welfare is no longer always a monotonic increasing function of the wife's wage, making the policy issues faced by society very different from those taken into account in traditional models of family taxation. It implies, in particular, that both spouses may achieve maximum utility under joint taxation, even if it implies a higher tax load for the secondary earner. Overall, our key insight that tax design will have to take account of not just the usual trade-off between equity and distortions caused by taxes, but will also have to try to correct the inefficiencies created by non-cooperative decision-making will continue to hold when one allows for preference heterogeneity among spouses.

Finally, we assume that a family public good is provided through time inputs into a simple household production process. In many cases, substitutes for home-produced public goods can be purchased in the market. While using this option does not make sense in a homogenous household framework with constant returns due to zero taxation of home production, secondary earners with a high wage rate may find it worthwhile to supply more labor and buy additional units of these substitutes in the market. Such a behavior would also be plausible with increasing returns in the production of those substitutes. Although underprovision problems continue to exist in such frameworks if the spouses do not coordinate the purchase of these substitutes, the efficiency argument in favor of joint taxation becomes somewhat weaker. 


\section{Conclusions}

This paper integrates two different strands of research on household behavior, on strategic family decision-making and on family taxation. Our analysis gives a sense of why family taxation issues may go beyond conventional labor supply elasticity considerations. The reason is that, with non-cooperative couples, an additional distortion, not mentioned in the previous literature, needs to be taken care of: the failure of spouses to internalize the collective effect of their actions. While conventional tax-induced labor supply distortions lead to excessive incentives for home production, the collective action problem points towards an underprovision of the household public good. Both distortions need to be taken into account in choosing whether to tax individuals or households.

Our results show that if individual tax rates are not excessively high, then the equilibrium provision of the home-produced public good is inefficiently low. In this case, the collective action problem becomes the dominant consideration in the optimal choice of tax unit, and a switch from individual to joint taxation generates a utility gain for both spouses. The source of Pareto-improvement consists in moving the provision of the household public good closer to the efficient level, while an increase in voluntary intra-family transfers compensates the secondary earner for the increased tax load.

We also demonstrate that the existence of a collective action problem at the family level in itself is not sufficient to guarantee the superiority of joint over individual taxation. If individual tax rates are sufficiently high and not too dispersed, then the household equilibrium suffers from an oversupply of the home-produced public good. In such a scenario, moving from individual to joint taxation reinforces incentives for home production, pushing the allocation further away from the Pareto frontier. This results in a utility loss for both partners, and provides an additional efficiency argument in favor of individual-based taxes.

A number of avenues for future research suggest themselves. A particularly interesting issue is to focus on the dynamics of marriage relationships. When spouses interact repeatedly it is possible to design relational or self-enforcing contracts so that any short-term incentive to behave non-cooperatively is offset by a long-term benefit from adhering to efficient patterns of behavior (Thomas and Worrall, 2010). It would interesting to study how alternative tax regimes affect the properties of such relational contracts. Future theoretical research in the area of family taxation might also explore other dynamic aspects of household behavior, such as the effects of different tax regimes on human capital investments or on marriage formation and dissolution. 


\section{References}

Anderberg, D. (2007), Inefficient households and the mix of government spending. Public Choice 131, 127-140.

Apps, P. and R. Rees (1999a), Individual versus joint taxation in models with household production. Journal of Political Economy 107, 393-403

Apps, P. and R. Rees (1999b), On the taxation of trade within and between households. Journal of Public Economics 73, 241-263.

Apps, P. and R. Rees (2007), The taxation of couples. IZA Discussion Paper, No. 2910, Bonn.

Barham, V., R.A Devlin and J. Yang (2009), A theory of rational marriage and divorce. European Economic Review 53, 93-106.

Del Boca, D. and C. Flinn (2009), Endogenous Household Interaction. Unpublished manuscript, New York University.

Gottfried, P. and W.F. Richter (1999), The Tax Unit and Household Production: Comment. Journal of Political Economy 107, 404-409.

Kleven, H.J., C. T. Kreiner and E. Saez (2009), The optimal income taxation of couples. Econometrica 77, 537-560.

Konrad, K.A. and K.E. Lommerud (1995), Family policy with non-cooperative families. Scandinavian Journal of Economics 97, 581-601.

Lundberg, S. and R. A. Pollak (1993), Separate spheres bargaining and the marriage market. Journal of Political Economy 101, 988-1010.

Meier, V. and M. Wrede (2008), Reducing the excess burden of subsidizing the stork: joint taxation, individual taxation and family tax splitting. CESifo Working Paper No. 2470, Munich.

Piggott, J. and J. Whalley (1996), The tax unit and household production. Journal of Political Economy 104, 398-418.

Pollak, R. A. (1985), A transaction cost approach to families and households. Journal of Economic Literature 23, 581-608. 
Rainer, H. (2007), Should we write prenuptial contracts? European Economic Review 51, 337-363.

Rasul, I. (2006), The economics of child custody. Economica 73, 1-25.

Thomas, J.P. and T. Worrall (2010), Dynamic relational contracts with credit constraints. Unpublished Manuscript, University of Manchester. 


\section{Appendix}

Proof of Lemma 1. The first-order condition determining labor supply for an interior solution reads

$$
\frac{w_{f}^{n}}{w_{f}^{n} \ell+\theta}-\frac{\beta_{f}}{1-\ell}=0
$$

Solving this condition for $\ell$ yields (9). As with very high transfer levels labor supply would be negative, effective labor supply is given by $\ell^{*}=\max \{0, \tilde{\ell}\}$, where $\ell^{*}=\tilde{\ell}>0$ if and only if $\theta<\hat{\theta}$. The comparative static results are immediate from (9).

Proof of Lemma 2. The first-order condition for an interior solution for the optimum transfer given an interior solution for the labor supply decision is

$$
-\frac{1}{w_{m}^{n}-\theta}+\frac{\beta_{m}}{[1-\tilde{\ell}(\theta)]} \cdot \frac{\beta_{f}}{\left(1+\beta_{f}\right) w_{f}^{n}}=0
$$

Inserting $\tilde{\ell}(\theta)$ from (9) and solving for $\theta$ yields (13). However, $\tilde{\theta}<0$ is not feasible and will be replaced by $\theta^{*}=0$. Further, $\tilde{\theta}>\hat{\theta}$ leads to negative labor supply of the wife, which is not admissible. As $\partial U_{m} / \partial \theta<0$ if $\ell=0, \theta^{*}=\hat{\theta}$ holds in such a situation. Comparative static results directly follow from (13).

Proof of Lemma 3. To prove the lemma, we plug (13) into (9), set $\alpha=0$ and $\beta_{m}=\beta_{f}=1$, and obtain:

$$
\tilde{\ell}\left(0, \tau_{j}, \tilde{\theta}\left(0, \tau_{j}\right)\right)=\frac{3}{4}-\frac{w_{m}}{4 w_{f}} .
$$

Similarly, by plugging (13) into (9), and setting $\alpha=1$ and $\beta_{m}=\beta_{f}=1$, we get

$$
\ell^{*}\left(1, \tau_{j}, \theta^{*}\left(1, \tau_{j}\right)\right)=\frac{3}{4}-\frac{w_{m}\left(1-\tau_{m}\right)}{4 w_{f}\left(1-\tau_{f}\right)} .
$$

It is now straightforward to establish the lemma by substituting (36) and (37) into (7) and then solving for $\tau_{j}$.

Proof of Proposition 1. The government's tax revenue under individual taxation is given by:

$$
\tilde{t}=\tau_{m} w_{m}+\tau_{f} w_{f} \ell^{*}\left(1, \tau_{j}, \theta^{*}\left(1, \tau_{j}\right)\right)
$$

Plugging (37) into (38), and the resulting expression into (22), the first-best provision level of the public good is:

$$
q^{e}=\left[\frac{4-3 \tau_{f}}{8}\right]\left[1+\frac{w_{m}\left(1-\tau_{m}\right)}{w_{f}\left(1-\tau_{f}\right)}\right]
$$

The private provision level under individual taxation is

$$
\tilde{q}_{I}=\frac{1}{4}\left[1+\frac{w_{m}\left(1-\tau_{m}\right)}{w_{f}\left(1-\tau_{f}\right)}\right]
$$


while under joint taxation it is given by

$$
\tilde{q}_{J}=\frac{1}{4}\left[1+\frac{w_{m}}{w_{f}}\right]
$$

Comparing (39) and (40), it follows immediately that

$$
\tilde{q}_{I} \gtreqless q^{e} \Longleftrightarrow \tau_{f} \gtreqless \frac{2}{3} \text {. }
$$

From (39) and (41), we obtain

$$
\tilde{q}_{J} \gtreqless q^{e} \Longleftrightarrow w_{m} \gtreqless \mu w_{f} \quad \text { where } \quad \mu=\frac{\left(2-3 \tau_{f}\right)\left(1-\tau_{f}\right)}{2\left(1-\tau_{f}\right)-\left(1-\tau_{m}\right)\left(4-3 \tau_{f}\right)} .
$$

Now, an interior equilibrium exists under both individual $(\alpha=1)$ and joint taxation $(\alpha=0)$ as long as $w_{m} \in\left(\underline{w}_{m}(0), \bar{w}_{m}(1)\right)$, where $\underline{w}_{m}(0)=\frac{\left(1-\tau_{f}\right) w_{f}}{1-\tau_{m}}$ and $\bar{w}_{m}(1)=3 w_{f}$. If $\tau_{m}>2 / 3$, then $\mu<\frac{1-\tau_{f}}{1-\tau_{m}}$, and hence $\tilde{q}_{J}>q^{e}$ for all $\left(w_{m}, w_{f}\right)$-pairs that give rise to an interior equilibrium. If $\tau_{m}<\frac{8+\tau_{f}\left(3 \tau_{f}-8\right)}{4-3 \tau_{f}} \equiv \tilde{\tau}_{m}$, then $\mu>3$, and hence $\tilde{q}_{J}<q^{e}$ for all $\left(w_{m}, w_{f}\right)$-pairs that give rise to an interior equilibrium. Finally, if $\tau_{m} \in\left(\tilde{\tau}_{m}, 2 / 3\right)$, then $\mu \in\left(\frac{1-\tau_{f}}{1-\tau_{m}}, 3\right.$ ), and hence $\tilde{q}_{J}>q^{e}$ (respectively, $\tilde{q}_{J}>q^{e}$ ) if $w_{m}>\mu w_{f}$ (respectively, if $\left.w_{m}<\mu w_{f}\right)$. This proves the proposition.

Proof of Proposition 2. From (23) and (24), it follows immediately that

$$
\tilde{U}_{J}^{i}>\tilde{U}_{I}^{i} \Longleftrightarrow \tau_{j}<1-\frac{\left[w_{m}\left(1-\tau_{f}\right)+w_{f}\left(1-\tau_{m}\right)\right]^{2}}{\left(1-\tau_{f}\right)\left(w_{m}+w_{f}\right)^{2}}
$$

Inserting the revenue-neutral joint tax rate [see equation (20)] into the left-hand side of the above inequality and solving for $w_{m}$, we obtain

$$
\tilde{U}_{J}^{i}>\tilde{U}_{I}^{i} \Longleftrightarrow w_{m}<\xi w_{f} \quad \text { where } \quad \xi=\frac{2-3 \tau_{f}}{3 \tau_{m}-2}
$$

Now, an interior equilibrium exists under both individual $(\alpha=1)$ and joint taxation $(\alpha=0)$ as long as $w_{m} \in\left(\underline{w}_{m}(0), \bar{w}_{m}(1)\right)$, where $\underline{w}_{m}(0)=\frac{\left(1-\tau_{f}\right) w_{f}}{1-\tau_{m}}$ and $\bar{w}_{m}(1)=3 w_{f}$. Clearly, if $\tau_{m}<\frac{8}{9}-\frac{\tau_{f}}{3} \equiv \underline{\tau}_{m}$, then $\xi>3$, and $\tilde{U}_{J}^{i}>\tilde{U}_{I}^{i}$ for all $\left(w_{m}, w_{f}\right)$-pairs that give rise to an interior equilibrium. This establishes the first part of the proposition. Next, if $\tau_{m}>\frac{5 \tau_{f}-4}{6 \tau_{f}-5} \equiv \bar{\tau}_{m}$, then $\xi<\frac{1-\tau_{f}}{1-\tau_{m}}$, and $\tilde{U}_{J}^{i}<\tilde{U}_{I}^{i}$ for all $\left(w_{m}, w_{f}\right)$-pairs that give rise to an interior equilibrium. This establishes the second part of the proposition. Finally, if $\tau_{m} \in\left(\underline{\tau}_{m}, \bar{\tau}_{m}\right)$, then $\xi \in\left(\frac{1-\tau_{f}}{1-\tau_{m}}, 3\right)$, and $\tilde{U}_{J}^{i}>\tilde{U}_{I}^{i}$ (respectively, $\left.\tilde{U}_{J}^{i}<\tilde{U}_{I}^{i}\right)$ if $w_{m}<\xi w_{f}$ (respectively, if $w_{m}>\xi w_{f}$ ). This establishes the final part of the proposition.

Proof of Proposition 3. In case of a no-transfer equilibrium with $\theta^{*}=0$ and $\ell^{*}=\tilde{\ell}(0)$, the revenue-neutral tax rate under joint taxation is

$$
\tilde{\tau}_{j}=\frac{2 \tau_{f} w_{f}+4 \tau_{m} w_{m}}{3\left(w_{m}+w_{f}\right)}
$$


Moreover, the utility level of the husband is

$$
\tilde{U}^{m}(\alpha)=\ln \left[\frac{w_{m}\left[1-\alpha \tau_{m}-(1-\alpha) \tilde{\tau}_{j}\right]}{2}\right],
$$

while that of the wife is given by

$$
\tilde{U}^{f}(\alpha)=\ln \left[\frac{w_{f}\left[1-\alpha \tau_{f}-(1-\alpha) \tilde{\tau}_{j}\right]}{4}\right] .
$$

Clearly, $\tilde{U}^{m}(0)>\tilde{U}^{m}(1)$ if and only if $\tilde{\tau}_{j}<\tau_{m}$, which requires

$$
w_{m}<\frac{w_{f}\left(3 \tau_{m}-2 \tau_{f}\right)}{\tau_{m}}
$$

Similarily, $\tilde{U}^{f}(1)>\tilde{U}^{f}(0)$ if and only if $\tau_{f}<\tilde{\tau}_{j}$ which requires

$$
w_{m}<\frac{-\tau_{f} w_{f}}{3 \tau_{f}-4 \tau_{m}}
$$

Note that a no-transfer equilibrium exists under both individual and joint taxation as long as $w_{m}<w_{f}$. It is now readily checked that $\frac{3 \tau_{m}-2 \tau_{f}}{\tau_{m}}>1$ and $\frac{-\tau_{f}}{3 \tau_{f}-4 \tau_{m}}>1$ for all $\tau_{m}>\tau_{f}$. Thus, the husband (respectively, the wife) achieves maximum utility under joint taxation (respectively, individual taxation) for all parameter values that give rise to a no-transfer equilibrium. 


\section{CESifo Working Paper Series}

for full list see www.cesifo-group.org/wp

(address: Poschingerstr. 5, 81679 Munich, Germany, office@cesifo.de)

3065 William E. Becker, William H. Greene and John J. Siegfried, Do Undergraduate Majors or Ph.D. Students Affect Faculty Size?, May 2010

3066 Johannes Becker, Strategic Trade Policy through the Tax System, May 2010

3067 Omer Biran and Françoise Forges, Core-stable Rings in Auctions with Independent Private Values, May 2010

3068 Torben M. Andersen, Why do Scandinavians Work?, May 2010

3069 Andrey Launov and Klaus Wälde, Estimating Incentive and Welfare Effects of NonStationary Unemployment Benefits, May 2010

3070 Simon Gächter, Benedikt Herrmann and Christian Thöni, Culture and Cooperation, June 2010

3071 Mehmet Bac and Eren Inci, The Old-Boy Network and the Quality of Entrepreneurs, June 2010

3072 Krisztina Molnár and Sergio Santoro, Optimal Monetary Policy when Agents are Learning, June 2010

3073 Marcel Boyer and Donatella Porrini, Optimal Liability Sharing and Court Errors: An Exploratory Analysis, June 2010

3074 Guglielmo Maria Caporale, Roman Matousek and Chris Stewart, EU Banks Rating Assignments: Is there Heterogeneity between New and Old Member Countries? June 2010

3075 Assaf Razin and Efraim Sadka, Fiscal and Migration Competition, June 2010

3076 Shafik Hebous, Martin Ruf and Alfons Weichenrieder, The Effects of Taxation on the Location Decision of Multinational Firms: M\&A vs. Greenfield Investments, June 2010

3077 Alessandro Cigno, How to Deal with Covert Child Labour, and Give Children an Effective Education, in a Poor Developing Country: An Optimal Taxation Problem with Moral Hazard, June 2010

3078 Bruno S. Frey and Lasse Steiner, World Heritage List: Does it Make Sense?, June 2010

3079 Henning Bohn, The Economic Consequences of Rising U.S. Government Debt: Privileges at Risk, June 2010

3080 Rebeca Jiménez-Rodriguez, Amalia Morales-Zumaquero and Balázs Égert, The VARying Effect of Foreign Shocks in Central and Eastern Europe, June 2010 
3081 Stephane Dees, M. Hashem Pesaran, L. Vanessa Smith and Ron P. Smith, Supply, Demand and Monetary Policy Shocks in a Multi-Country New Keynesian Model, June 2010

3082 Sara Amoroso, Peter Kort, Bertrand Melenberg, Joseph Plasmans and Mark Vancauteren, Firm Level Productivity under Imperfect Competition in Output and Labor Markets, June 2010

3083 Thomas Eichner and Rüdiger Pethig, International Carbon Emissions Trading and Strategic Incentives to Subsidize Green Energy, June 2010

3084 Henri Fraisse, Labour Disputes and the Game of Legal Representation, June 2010

3085 Andrzej Baniak and Peter Grajzl, Interjurisdictional Linkages and the Scope for Interventionist Legal Harmonization, June 2010

3086 Oliver Falck and Ludger Woessmann, School Competition and Students' Entrepreneurial Intentions: International Evidence Using Historical Catholic Roots of Private Schooling, June 2010

3087 Bernd Hayo and Stefan Voigt, Determinants of Constitutional Change: Why do Countries Change their Form of Government?, June 2010

3088 Momi Dahan and Michel Strawczynski, Fiscal Rules and Composition Bias in OECD Countries, June 2010

3089 Marcel Fratzscher and Julien Reynaud, IMF Surveillance and Financial Markets - A Political Economy Analysis, June 2010

3090 Michel Beine, Elisabetta Lodigiani and Robert Vermeulen, Remittances and Financial Openness, June 2010

3091 Sebastian Kube and Christian Traxler, The Interaction of Legal and Social Norm Enforcement, June 2010

3092 Volker Grossmann, Thomas M. Steger and Timo Trimborn, Quantifying Optimal Growth Policy, June 2010

3093 Huw David Dixon, A Unified Framework for Using Micro-Data to Compare Dynamic Wage and Price Setting Models, June 2010

3094 Helmuth Cremer, Firouz Gahvari and Pierre Pestieau, Accidental Bequests: A Curse for the Rich and a Boon for the Poor, June 2010

3095 Frank Lichtenberg, The Contribution of Pharmaceutical Innovation to Longevity Growth in Germany and France, June 2010

3096 Simon P. Anderson, Øystein Foros and Hans Jarle Kind, Hotelling Competition with Multi-Purchasing: Time Magazine, Newsweek, or both?, June 2010 
3097 Assar Lindbeck and Mats Persson, A Continuous Theory of Income Insurance, June 2010

3098 Thomas Moutos and Christos Tsitsikas, Whither Public Interest: The Case of Greece's Public Finance, June 2010

3099 Thomas Eichner and Thorsten Upmann, Labor Markets and Capital Tax Competition, June 2010

3100 Massimo Bordignon and Santino Piazza, Who do you Blame in Local Finance? An Analysis of Municipal Financing in Italy, June 2010

3101 Kyriakos C. Neanidis, Financial Dollarization and European Union Membership, June 2010

3102 Maela Giofré, Investor Protection and Foreign Stakeholders, June 2010

3103 Andrea F. Presbitero and Alberto Zazzaro, Competition and Relationship Lending: Friends or Foes?, June 2010

3104 Dan Anderberg and Yu Zhu, The Effect of Education on Martial Status and Partner Characteristics: Evidence from the UK, June 2010

3105 Hendrik Jürges, Eberhard Kruk and Steffen Reinhold, The Effect of Compulsory Schooling on Health - Evidence from Biomarkers, June 2010

3106 Alessandro Gambini and Alberto Zazzaro, Long-Lasting Bank Relationships and Growth of Firms, June 2010

3107 Jenny E. Ligthart and Gerard C. van der Meijden, Coordinated Tax-Tariff Reforms, Informality, and Welfare Distribution, June 2010

3108 Vilen Lipatov and Alfons Weichenrieder, Optimal Income Taxation with Tax Competition, June 2010

3109 Malte Mosel, Competition, Imitation, and R\&D Productivity in a Growth Model with Sector-Specific Patent Protection, June 2010

3110 Balázs Égert, Catching-up and Inflation in Europe: Balassa-Samuelson, Engel’s Law and other Culprits, June 2010

3111 Johannes Metzler and Ludger Woessmann, The Impact of Teacher Subject Knowledge on Student Achievement: Evidence from Within-Teacher Within-Student Variation, June 2010

3112 Leif Danziger, Uniform and Nonuniform Staggering of Wage Contracts, July 2010

3113 Wolfgang Buchholz and Wolfgang Peters, Equity as a Prerequisite for Stable Cooperation in a Public-Good Economy - The Core Revisited, July 2010 
3114 Panu Poutvaara and Olli Ropponen, School Shootings and Student Performance, July 2010

3115 John Beirne, Guglielmo Maria Caporale and Nicola Spagnolo, Liquidity Risk, Credit Risk and the Overnight Interest Rate Spread: A Stochastic Volatility Modelling Approach, July 2010

3116 M. Hashem Pesaran, Predictability of Asset Returns and the Efficient Market Hypothesis, July 2010

3117 Dorothee Crayen, Christa Hainz and Christiane Ströh de Martínez, Remittances, Banking Status and the Usage of Insurance Schemes, July 2010

3118 Eric O’N. Fisher, Heckscher-Ohlin Theory when Countries have Different Technologies, July 2010

3119 Huw Dixon and Hervé Le Bihan, Generalized Taylor and Generalized Calvo Price and Wage-Setting: Micro Evidence with Macro Implications, July 2010

3120 Laszlo Goerke and Markus Pannenberg, 'Take it or Go to Court' - The Impact of Sec. 1a of the German Protection against Dismissal Act on Severance Payments -, July 2010

3121 Robert S. Chirinko and Daniel J. Wilson, Can Lower Tax Rates be Bought? Business Rent-Seeking and Tax Competition among U.S. States, July 2010

3122 Douglas Gollin and Christian Zimmermann, Global Climate Change and the Resurgence of Tropical Disease: An Economic Approach, July 2010

3123 Francesco Daveri and Maria Laura Parisi, Experience, Innovation and Productivity Empirical Evidence from Italy’s Slowdown, July 2010

3124 Carlo V. Fiorio and Massimo Florio, A Fair Price for Energy? Ownership versus Market Opening in the EU15, July 2010

3125 Frederick van der Ploeg, Natural Resources: Curse or Blessing?, July 2010

3126 Kaisa Kotakorpi and Panu Poutvaara, Pay for Politicians and Candidate Selection: An Empirical Analysis, July 2010

3127 Jun-ichi Itaya, Makoto Okamura and Chikara Yamaguchi, Partial Tax Coordination in a Repeated Game Setting, July 2010

3128 Volker Meier and Helmut Rainer, On the Optimality of Joint Taxation for NonCooperative Couples, July 2010 